\title{
Stem cells and tissue engineering: an alternative treatment for craniofacial congenital malformations and articular degenerative diseases
}

\author{
Cristina Velasquillo", ${ }^{1, *}$ Antonio Madrazo-Ibarra ${ }^{1, *}$, Claudia Gutiérrez-Gómezz,2, Marcia Rosario Pérez- \\ Dosal $^{3}$, Yaaziel Melgarejo-Ramírez ${ }^{1}$, Clemente Ibarra ${ }^{4}$ \\ 'Biotecnología, Instituto Nacional de Rehabilitación LGII, Ciudad de México 14389, México. \\ ${ }^{2}$ Hospital General Dr. Manuel Gea González and Instituto Nacional de Rehabilitación LGII, Ciudad de México 14080, México. \\ ${ }^{3}$ Médico Adscrito al Servicio de Cirugía Plástica, Instituto Nacional de Pediatría, Ciudad de México 04530, México. \\ ${ }^{4}$ Dirección General, Instituto Nacional de Rehabilitación LGII, Ciudad de México 14389, México. \\ *These authors contributed equally to this work as first.
}

Correspondence to: Dr. Cristina Velasquillo, Biotecnología, Instituto Nacional de Rehabilitación LGII, Ciudad de México 14389, México. E-mail: mvelasquillo@ciencias.unam.mx; and Dr. Clemente Ibarra, Dirección General, Instituto Nacional de Rehabilitación LGII, Ciudad de México 14389, México. E-mail: clementeibarra@yahoo.com

How to cite this article: Velasquillo C, Madrazo-Ibarra A, Gutiérrez-Gómez C, Pérez-Dosal MR, Melgarejo-Ramírez Y, Ibarra C. Stem cells and tissue engineering: an alternative treatment for craniofacial congenital malformations and articular degenerative diseases. Plast Aesthet Res 2020;7:31. http://dx.doi.org/10.20517/2347-9264.2020.30

Received: 4 Mar 2020 First Decision: 15 May 2020 Revised: 2 Jun 2020 Accepted: 9 Jun 2020 Published: 24 Jun 2020

Science Editor: Yi-Lin Cao Copy Editor: Cai-Hong Wang Production Editor: Tian Zhang

\begin{abstract}
The life quality of patients with craniofacial malformations is severely affected by the physical disabilities caused by the malformation itself, but also by being subjected to bullying, which leads to a series of relevant psychological and societal effects that have an economic impact on the health sector. Orofacial clefts, notably cleft lip (CL), cleft palate, and microtia, are the most common craniofacial birth defects in humans and represent a substantial burden, both personal and societal. On the other hand, osteoarthritis is a widespread degenerative disease that is becoming more common due to the extension of the human lifespan and to an increase in injuries in young people as a result of their lifestyle. Advances in tissue engineering as a part of regenerative medicine offer new hope to patients that can benefit from new tissue engineering therapies based on the supportive action of tailored $3 \mathrm{D}$ biomaterials and the synergic action of stem cells that can be driven to the process of bone and cartilage regeneration. This review provides an update on recent considerations for stem cells and studies on the use of advanced biomaterials and cell therapies for the regeneration of craniofacial congenital malformations and articular degenerative diseases.
\end{abstract}

Keywords: Mesenchymal stromal cells, microtia, cartilage, cleft lip, cleft palate 


\section{INTRODUCTION}

According to the National Cancer Institute, degenerative disease is a pathology in which the function or structure of the affected tissues or organs worsens over time ${ }^{[1]}$. Unfortunately, neither most degenerative diseases nor craniofacial congenital malformation diseases have a cure, so they evolve until patients become severely disabled. Since stem cells became an alternative treatment, they have changed the course of these diseases. Their applications are currently being tested and have shown positive results in several of these diseases.

Stem cells are cells with self-renewal and differentiation abilities. Mesenchymal stem cells (MSC) are adult stem cells that are not hematopoietic and can be found in several tissues, such as adipose tissue, bone marrow, and umbilical cord, to mention some examples. According to the International Society for Cell Therapy (ISCT), MSC must (1) be plastic-adherent; (2) express CD105, CD73, and CD90; (3) lack CD45, CD34; and (4) differentiate into osteoblasts, adipocytes, and chondroblasts ${ }^{[2]}$; however, these criteria do not suffice to justify their therapeutic potential ${ }^{[3]}$. Besides their differentiation ability, MSC have paracrine activity in angiogenesis, cellular activation/proliferation, and immunomodulation ${ }^{[4,5]}$. Since they were first introduced in 1970 by Friedenstein, MSC have changed the treatment of individuals with orthopedic, hematologic, oncologic, ophthalmologic and dermatologic conditions. They have been used mainly to replace cell lines that have been lost or destroyed or to modify the behavior of other cells.

In this paper, we will briefly describe the applications of MSC in common degenerative and congenital diseases in Mexico.

\section{DEFINING THE REGENERATIVE POTENTIAL OF MSC BEYOND BIOLOGY}

For many years, the use of autologous cells isolated directly from biopsies was the only alternative for tissue engineering applications. Fully differentiated cells tend to lose cellular features if they are exposed to a constant cellular division. These cellular features include changes in the extracellular matrix (ECM), protein synthesis, altered metabolism, and dedifferentiation. Regenerative therapies commonly need a high number of cells, leading to the search of cells with high regenerative potential and no risk of morphological features loss. Mesenchymal stromal cells have become a promising alternative since they are one of the first cells in cellular lineage with unlimited fashion propagation and an extensive differentiation ability ${ }^{[3]}$.

The analysis of the potential of MSC for therapeutic purposes can be conducted at different stages. Typically, the mesenchymal phenotype according to the ISCT criteria should be verified; however, additional surface markers have been described, which include being positive for CD29, and negative for CD14, CD11b CD19, CD79 alpha, and HLA-DR surface markers. Differentiation protocols can also be analyzed based on the expression of these markers in chondrogenic, adipogenic, or osteogenic lineages. For example, osteogenic differentiation can be confirmed with alkaline phosphatase activity, calcium release after osteogenic stimulation, catalase (osteoclast inhibitor), and glutathione peroxidase 3 (osteogenic biomarker) expression ${ }^{[6]}$. Transcriptional analysis at mRNA levels is another alternative to track the therapeutic potential of MSC. It is possible to estimate cellular growth and colony-forming potential quantifying the MSC marker STRO- 1 and the platelet-derived growth factor receptor A (PDGFR-alpha). A transcriptional increase of Twist-related protein-1 (TWIST-1) and Twist-related protein-2 (DERMO-1) has also been described as crucial for MSC growth and development ${ }^{[7]}$.

There has been a continuous debate about whether autologous or heterologous cells are the most adequate source of MSC in regenerative therapies for congenital and craniofacial diseases. Their immunomodulatory ability is a relevant aspect exerted through the inhibition of T-cell proliferation, which regulates the immune response, and is also involved in the alloimmune response. Autologous MSC have been shown to decrease in vitro alloimmune response in host autologous cells in transplanted murine models. It has 
been proposed that the homing activity of MSC creates immune-privileged sites that limit the infiltration of $\mathrm{CD} 4+$ and $\mathrm{CD} 8+\mathrm{T}$ cells in tissues, thus limiting damage and promoting regeneration ${ }^{[8]}$. Meanwhile, heterologous MSC from bone marrow (BM-MSC) have been used for the treatment of pseudoarthrosis and have been proved to promote healing of femoral fractures in a claudication animal model. Heterologous BM-MSC reached the lesion $24 \mathrm{~h}$ after being infused, and later promoted a periosteal reaction that lead to fracture consolidation and cartilage formation 120 days after the infusion. In comparison, BM-MSC alone formed a fibro-osteoid tissue ${ }^{[9]}$. These effects lead us to elucidate that the use of autologous versus allogeneic MSC will depend on the required clinical outcome.

In recent years, clinical implications and advantages in the use of stromal vascular fraction (SVF) have opened new alternatives for tissue engineering in craniofacial or degenerative diseases. The differences between SVF and adipose-derived MSC (AD-MSC) are that an SVF is a freshly harvested, heterogeneous population of cells directly isolated from lipoaspirates by mechanical or enzymatic disaggregation that contains stromal cells (15\%-30\%), erythrocytes, granulocytes, monocytes, pericytes, and endothelial cells ${ }^{[10]}$. AD-MSC are a cultured, more homogeneous subpopulation of cells resulting from a culture selection and in vitro expansion. On the other hand, compared to BM-MSC, adipose tissue contains 100-500 fold more MSC, and SVF contains 4-6 fold more MSC, whose therapeutic impact, angiogenic stimulation, T-cell regulation and reduction of IL-10 production represent a feasible source for tissue engineering ${ }^{[11]}$.

Although there are still difficulties to establish the proper dose and clinical safety protocols, there is no doubt of the potential of AD-MSC to accelerate healing processes. Therapeutic efforts for the treatment of degenerative diseases have moved research groups to develop semi-automated, surgically-closed systems to obtain SVF during surgeries with minimal laboratory equipment requirements that will enable the application and implantation of autologous or heterologous MSC for tissue engineering ${ }^{[12]}$.

\section{Degenerative diseases}

A degenerative disease is a pathology in which the function or structure of the affected tissues or organs worsens over time ${ }^{[1]}$. As mentioned earlier, stem cells have changed the course of these diseases and have become an alternative treatment for degenerative disorders.

\section{Osteoarthritis}

Osteoarthritis (OA) is a condition that causes joints to hurt and become stiff. It is the most common cause of arthritis worldwide, and it mainly affects knees (85\%), hips, hands, and feet. Approximately 240 million people in the world have $\mathrm{OA}^{[13]} .5 \%$ of adults worldwide have either hip or knee OA. These numbers will increase as the population ages and the obesity rates increases ${ }^{[14]}$. Pain is the main symptom that typically leads patients to seek medical care and guides clinicians into treatment decision-making as well. Pain can be so intense, patients become unable to work, making OA the fourth leading cause of years lived with disability worldwide ${ }^{[15]}$.

OA has been part of the changes of articular cartilage, but that concept has evolved, now considering the whole joint ${ }^{[16,17]}$. Some of the structural damages of joints are (1) loss of cartilage; (2) osteophyte formation; (3) subchondral bone changes; and (4) meniscal alterations ${ }^{[17]}$. Chondral erosions caused by overload or abnormal joint kinematics turn into fissures. In an attempt to repair these lesions, hypertrophic chondrocytes increase their synthetic activity, but, by doing that, they increase the production of proinflammatory mediators and degradation products. These molecules stimulate surrounding synovium, increasing its proliferation, and proinflammatory response as well. All inflammation mediators favor endochondral ossification, causing bone overgrowth and osteophyte formation. Pain comes from the peripheral nociceptors sensing ongoing tissue injury, as well as inflammation in the joint ${ }^{[16]}$. 
Nowadays, treatment towards $\mathrm{OA}$ is oriented towards minimizing pain, optimizing function, and modifying the process of joint damage. Pain control, as mentioned earlier, is what guides the physician's decision into which treatment to use. Analgesics and anti-inflammatory medications are the mainstay treatment, accompanied by lifestyle modifications such as weight loss and physical therapy/activity ${ }^{[18]}$. Since no medication has been shown to stop the process of OA, measures have been taken to prevent it. Focal cartilage lesions, if left untreated, tend to quickly progress into osteoarthritis.

A retrospective study performed in the National Institute of Rehabilitation in Mexico reported that 61\% of the patients undergoing arthroscopic surgery had focal chondral lesions in the knee, with $74 \%$ of these being grade III-IV ICRS/Outerbridge ${ }^{[19]}$. Cartilage reparation techniques, such as microfractures, autologous chondrocyte implantation, and mosaicplasty have shown to delay the appearance of OA, as well as the need for total joint replacement after chondral injuries in young adults ${ }^{[20-23]}$. Some biological therapies have been researched, including drugs that promote chondrogenesis and osteogenesis ${ }^{[24]}$, matrix degradation inhibitors, apoptosis inhibitors, and anti-inflammatory cytokines ${ }^{[25]}$; however, none of them have demonstrated sufficient symptom improvement to be included in the standard of care ${ }^{[26]}$.

Mesenchymal stem cells have turned into the most explored therapeutic drug in cell-based OA treatment due to their ability to differentiate to chondrocytes and their immunomodulatory properties ${ }^{[27]}$. Furthermore, they have been used in different ways to try and modify the course of the disease.

\section{MSC seeded on scaffolds}

Cartilage implants: by taking advantage of the differentiation capacity of MSC to chondrocytes, MSC have been similarly used for cartilage lesion repair as matrix-assisted autologous chondrocyte implants. Previous studies using chondrocytes seeded on collagen or polyglycolic-acid matrixes have shown good mid- to long-term clinical and magnetic resonance imaging (MRI) outcomes, as well as the ability to delay degenerative changes in the knee ${ }^{[28-31]}$.

A few years ago, the United States Food and Drug Administration approved MACI, a porcine collagen membrane seeded with autologous chondrocytes, for the treatment of focal chondral lesions in the knee ${ }^{[32]}$. Okano et al. ${ }^{[33]}$ came up with the "cell sheet technology" consisting of multiple cell layers placed on top of another (instead of using a matrix), taking advantage of the intact ECM produced by the cultured chondrocytes and their adhesion factors. This innovative technique has been shown to form hyaline cartilage in preclinical studies and is currently undergoing clinical studies in $\operatorname{Japan}^{[34-36]}$. Even though these techniques have had great outcomes, they involve two surgical procedures: one to obtain the cartilage biopsy and the second one for the implantation. This makes the intervention expensive and may increase the risk of surgical complications. MSC seeded on a 3-dimensional scaffold or using the cell sheet technology can help solve this problem. Due to endogenous cell stimulation, MSC differentiate into cartilage, forming a cartilage-like tissue repair ${ }^{[37]}$. Several clinical and preclinical studies using MSC seeded on matrixes have shown positive results in forming cartilage-like tissue and alleviating symptoms ${ }^{[38,39]}$.

In 2015, Kim et al. ${ }^{[40]}$ conducted a comparative matched paired analysis comparing injected vs surgically implanted MSC in patients with knee osteoarthritis. Patients were evaluated with Patient-Reported Outcome Measures (PROMs), as well as a second-look arthroscopy. After a minimum follow-up of 24 months, patients who underwent MSC implantation showed better clinical and second-look arthroscopic outcomes. Despite the positive findings with this technique, it is usually employed to repair small defects and does not address larger areas related to OA. Problems related to the acquisition of autologous MSC and the risk of graft-versus-host reactions with allogeneic MSC have limited their use in clinical studies.

Meniscus repair: menisci play an important role in load-bearing and load transmission to the cartilage and subchondral bone. Approximately $15 \%$ of knee lesions are associated with damage to the meniscus ${ }^{[41]}$. 
Meniscal lesions generate knee instability and further cartilage damage favoring the development of OA. Treatment for meniscal lesions is decided depending on the complexity and the location of the damage. Repair strategies are used when the rupture is small, located in the vascular areas, and the meniscus can be stabilized intra-articularly. However, partial meniscectomy or complete meniscectomy is required in complex lesions. Meniscectomies cause an increase of $235 \%$ contact pressure ${ }^{[42]}$, as well as an increase in OA incidence ${ }^{[43-45]}$. The use of meniscal substitutes after partial meniscectomy has shown symptom relief, as well as a slow decrease of articular degeneration; however, they do not prevent it ${ }^{[46,47]}$.

Leroy et al ${ }^{[46]}$ reported a decrease in scaffold dimensions leading to a concern about the scaffold's capacity in the long term. The use of MSC in combination with meniscal substitutes have become of great interest due to the evidence of meniscal-like tissue formation after implantation in rats, pigs, and rabbits ${ }^{[48,49]}$. Olivos-Meza et al. ${ }^{[50]}$ conducted a comparative study between patients who received meniscal substitution with acellular polyurethan meniscal scaffolds (APS) vs. polyurethane scaffold enriched with peripheral blood MSC (MPS). They evaluated femoral and tibial articular cartilage status using MRI T2-mapping 3, 6, 9, and 12 months after surgery, as well as clinical evaluation using PROMs. No differences were observed between APS and MPS during the 12-month follow-up; however, a longer follow-up is needed to see the scaffold degeneration and tissue formation.

MSC exosomes: exosomes are extracellular vesicles that function as intercellular communication vehicles transferring lipids, nucleic acids (mRNA and microRNAs) and proteins to generate a response in recipient cells ${ }^{[51]}$. Exosomes are rich in microRNA, which can bind specific sites in transcribed mRNA, modifying their expression and transduction ${ }^{[51,52]}$. These properties have been studied to promote cartilage regeneration and decrease pro-inflammatory molecules in $\mathrm{OA}^{[53-57]}$. Tao et al. ${ }^{[56]}$ and Toh et al. ${ }^{[58]}$ reported several microRNAs (140-5p, 23b, 92a, 125b, 320, 145, 22 and 221) derived from human synovial MSC, which promote cartilage regeneration, $\mathrm{OA}$ suppression, and cartilage/extracellular matrix homeostasis in preclinical studies. The exosomes' potential for OA treatment, good tolerance, and minimal risk of immunogenicity and toxicity has made them one of the most important hotspots for future research. However, further studies describing how to obtain large-scale purified exosomes as well as their clinical efficacy and biosecurity are still needed.

Intra-articular injections: intra-articular injections of MSC have become the main modality of cell therapy research for $\mathrm{OA}$ treatment due to their simple application thanks to their anti-inflammatory, immuneregulatory, and regenerative abilities. MSC can be either injected with no other components or mixed with hyaluronic acid (HA), platelet-rich plasma (PRP), or saline solution, to mention some examples. Preclinical studies have shown cartilage repair, reduction in proinflammatory cytokines, and improved imaging, morphology, and histology ${ }^{[5,60]}$. Mixed injections with PRP/MSC or HA/MSC have shown significantly better results on the repaired cartilage than individual uses of any of them.

Several clinical trials have been developed worldwide using MSC derived from the stromal vascular fraction (SVF), umbilical cord (UC-MSC), adipose tissue (AD-MSC) or bone-marrow (BM-MSC), the latter being the most common site. BM-MSC have shown a better chondrogenic ability compared to ADMSC $^{[61]}$ and have shown an improvement in cartilage quality and knee function, as well as a decrease in pain and other symptomatologies ${ }^{[27]}$. Most clinical trials that use AD-MSC and SVF have been conducted using mixed injections combined with PRP. Results have been positive, showing an increase in cartilage thickness, significant positive changes in MRI, and symptomatology improvement ${ }^{[62]}$. Few trials have been done using UC-MSC. Cartistem is the first approved allogeneic cell treatment for OA in the world. It was approved by the Ministry of Food and Drug Safety in Korea and is now commercially available ${ }^{[63]}$. It uses UC-MSC combined with sodium hyaluronate. Up to 5000 patients have been treated with Cartistem and around $97.67 \%$ of them have shown improved quality of life ${ }^{[63,64]}$. 


\section{Congenital anomalies}

Congenital anomalies, also known as birth defects, are structural or functional anomalies that occur during intrauterine life ${ }^{[6]}$. These defects can be identified prenatally, at birth, or even during later infancy. They occur in $2 \%-4 \%$ of live births ${ }^{[66]}$ and are more common in stillborn spontaneous miscarriages. Approximately $50 \%$ of all congenital anomalies are not linked to a specific cause ${ }^{[6]}$; however, they are commonly caused by genetic abnormalities and/or environmental exposures. Genetic abnormalities include chromosomal alterations (e.g., Down syndrome) or single-gene/monogenic disorders. The latter have different modes of inheritance such as autosomal dominant, autosomal recessive, or X-linked ${ }^{[67]}$. On the other hand, environmental exposure to a teratogen, any agent that causes abnormalities in the form or function of the fetus, can produce cell death, alter normal growth of tissues, or interfere with normal cellular differentiation, resulting in a congenital anomaly ${ }^{[68]}$.

Birth defects are divided depending on the pathophysiology of the defect: (1) malformation when the intrinsic development is abnormal; (2) deformation when extrinsic mechanical forces modify a normally formed structure; (3) disruption when a vascular defect causes a malformation; or (4) dysplasia when there is an abnormal organization of cells into tissues ${ }^{[68]}$. These defects can be isolated or present in syndromes or associated patterns that may affect one or more organ systems. A lot of preventive measures, as well as treatment measures, have been focused on these anomalies due to their medical, surgical, psychological, and cosmetic significance.

\section{Congenital microtia}

Congenital microtia is the incomplete formation or growth of the auricle, leading to the small or deformed auricle. It may occur as an isolated condition or as part of a syndrome or spectrum of anomalies. Microtia severity ranges from a complete absence of the auricle (anotia) to a mild size discrepancy. Most of the time, microtia occurs unilaterally (79\%-93\%), the right side being the most affected side ${ }^{[60]}$. It is associated with hearing loss of the ipsilateral ear, but normal hearing in the unaffected ear. Speech and language development are usually normal. Individuals with microtia, however, are at a higher risk of communication delay and attention deficit disorders ${ }^{[70,71]}$.

The etiology of microtia is poorly understood, though there is strong evidence supporting the importance of environmental causes such as altitude, and gestational exposure to certain drugs ${ }^{[72-75]}$. Ethnicity has been reported to be an important consideration due to the high incidence and prevalence of microtia among Asians, Hispanics, and Native Americans. In Mexico, the World Health Organization and the Mexican Registry and Epidemiological Surveillance of External Congenital Malformations (RYVEMCE) reported a prevalence of 6.15-7.37 cases per 10,000 childbirths, being one of the countries with the highest prevalence of microtia worldwide ${ }^{[72,75]}$. Due to the psychological and functional implications related to microtia, there have been several studies focusing on the surgical treatment and biotechnology measures needed to recreate an auricle as similar as possible to the native one.

Auricle reconstruction with autologous rib cartilage remains the gold standard for patients with microtia/ anotia. Tanzer et al. ${ }^{[76]}$ and Brent et al. ${ }^{[77]}$ described this technique as an alternative to allogeneic implants in the late 1950s, overcoming several problems associated with these implants. Sculpted autologous costal cartilage graft is one of the most challenging procedures in plastic and reconstructive surgery since the surgeon has to handcraft the cartilage trying to create an ear similar in appearance to the contralateral one. Grafts have good long-term durability and grow concomitantly as the patient ages ${ }^{[77]}$. However, costal cartilage grafts are not as consistent as synthetic implants: they require long operative time, harvesting results in donor-site morbidity, and, occasionally, there is an insufficient source of cartilage.

Tissue engineering techniques emerged as an alternative treatment. The idea of preformed ear structures seeded with cells goes back to the 1940 s when Peer et al. ${ }^{[78]}$ started using diced cartilage placed inside an 
auricle shaped mold. Research started focusing on scaffolds that could promote cell proliferation, as well as matrix production. Decades later, research focused on finding the ideal scaffold that would induce cellular proliferation and cartilage tissue formation. This was proved by Vacanti et al. ${ }^{[79]}$ and Rodriguez et al. ${ }^{[80]}$, who conducted several preclinical studies showing that polyglycolic acid (PGA) + polylactic acid (PLA) would promote in vitro cell proliferation and matrix production, and in vivo cartilage formation after implantation. Mice were implanted with 3D ear-shaped scaffolds seeded with chondrocytes. After 12 weeks, scaffolds were almost entirely degraded; however, the neo-tissue maintained the original 3D structure and demonstrated histological cartilage appearance. These studies were the introduction of biotechnology to regenerative medicine ${ }^{[81]}$.

The combination of seeded auricular chondrocytes (AuCs) to scaffolds and the computer-assisted design/ computer-aided manufacturing $(\mathrm{CAD} / \mathrm{CAM})$ technology ${ }^{[82-84]}$ led to the start of clinical studies. The first clinical application was done in Shanghai in 2018 by Guangdong Zhou et al ${ }^{[84]}$, where 5 patients with unilateral microtia were implanted with 3D printed PCL + PGA scaffolds seeded with autologous chondrocytes from the cartilage remnants of the microtia. 2.5 years later, they reported the follow-up of one patient showing the formation of cartilaginous tissue after histologic evaluation, the transition from a stiff graft to a more flexible one over the time, and the degradation of the scaffold without losing the original ear shape.

Currently, autologous chondrocytes from the microtia auricle are being isolated, expanded, and seeded onto the constructs, showing normal elastic cartilage on histology ${ }^{[85]}$. However, monolayer expansion of chondrocytes results in dedifferentiation ${ }^{[80,86]}$, limiting the capacity to generate robust cartilage, and needs extensive $3 \mathrm{D}$ construct culture before implantation ${ }^{[84,87]}$. Mesenchymal stem cells have the potential of massive expansion and the ability to differentiate into chondrocytes through co-culture or coimplantation ${ }^{[88]}$.

Studies have been done using articular cartilage co-cultures with MSC, though little is known about AuCs and MSC. Pre-clinical in vivo studies have shown the formation of cartilage, but the impact of these studies is limited due to the use of non-human cells, the lack of specific markers for elastic cartilage, and the absence of mechanical evaluation ${ }^{[89-94]}$. Cohen et al. ${ }^{[95]}$ conducted a comparative preclinical study evaluating cartilage formation in constructs using human AuCs vs human AuCs and MSC in a 1:1 ratio. The study showed that the auricular cartilage generated in the 1:1 constructs was similar in structure, histology, biochemical development, and mechanical properties to discs containing only AuCs and native human auricular cartilage after 3 months in vivo. To date, no clinical study using AuCs in combination with MSC has been conducted. However, these findings suggest MCSs could solve several problems related to cartilage culture and could bring other benefits related to their immunomodulatory/anti-inflammatory potential.

\section{Cleft lip and palate}

Cleft lip (CL) and palate (CLP) are common congenital malformations in Mexico, with an incidence of 1 in 800 births $^{[96]}$. Up to 2003, CLP had a prevalence of 139,000 affected children throughout the country, with approximately 10 new cases identified daily ${ }^{[97]}$.

Patients with CLP undergo (on average) 4 surgical procedures during their lifetime: (1) lip closure and primary nasal repair; (2) palate closure; (3) alveolar bone graft; and (4) rhinoseptoplasty ${ }^{[98]}$. The alveolar bone graft is the placing of bone in the primary palate to restore the continuity of the maxillary arch and separate the oral and nasal cavity ${ }^{[99,100]}$. This allows adequate dental hygiene, promotes harmonic facial growth, and provides the necessary bone matrix for the eruption of the lateral and canine incisors ${ }^{[101,102]}$.

The best donor area for the bone graft is the iliac crest, where approximately $3-8 \mathrm{~cm}^{3}$ of bone are obtained. Several problems are associated with this procedure, such as recipient area alterations (lack of integration, 
bone sequestration, infection or bone resorption), donor area complications (hematoma, infection, abnormal scar, pain and temporary inability to walk $)^{[103]}$, and insufficient bone graft ${ }^{[104,105]}$. In these cases, the possibility of synthetic bone substitutes (silicone, polytetrafluoroethylene, polyethylene, polyester, polyamides, acrylic, metals, cyanoacrylate, resins) ${ }^{[106-111]}$, or natural bone substitutes (calcium phosphate, granules) has been suggested ${ }^{[12-119]}$.

The use of cell-based therapy represents one of the most advanced methods to approach craniofacial abnormalities. Several animal models have been used to test alveolar cleft-grafting materials including mice, rabbits, cats, dogs, goats, sheep, and monkeys. Studies have shown heterogeneous results in terms of biocompatibility, bone regeneration capacity, integration, resorption, and mechanical resistance due to the physicochemical characteristics of each material ${ }^{[120,121]}$. Existing systematic reviews support the ability of bone regeneration on these materials for the treatment of small periodontal bone defects, but recommend further studies on major bone defects such as palatal fissures ${ }^{[122-124]}$.

Scaffolds, as in all biotechnology-related applications, have been a major research topic regarding CLP. The ideal scaffold should have macro-geometry, micro-architecture, bioactivity, and appropriate mechanical properties ${ }^{[125]}$. The first two characteristics have been addressed with the introduction of $3 \mathrm{D}$ printed scaffolds. A head CT scan is performed in patients with CLP, and a scaffold with the patient's exact macroscopic geometry is created. Bioactivity and mechanical properties are determined by the scaffold material. Several different materials like polycaprolactone (PCL) with hydroxyapatite and platelet-derived growth factor- $\mathrm{BB}^{[125]}$, cryogels ${ }^{[126]}$, demineralized bone matrices, PLA, among others, have been tested to evaluate bone regeneration and cellular migration ${ }^{[127-131]}$. Today, the use of bioceramics, such as calcium phosphate, in combination with biomimetic polymer scaffolds, folic acid derivatives, morphogens, and stem cells are currently considered the most promising alternatives for CLP regeneration ${ }^{[127]}$.

The use of mesenchymal stem cells is emerging as an alternative treatment or in combination with previously-described therapies for patients with CLP. As mentioned earlier, MSC can be obtained from different parts of the body such as adipose tissue, bone marrow, and umbilical cord. The generation of an artificial alveolar cleft and the implantation of teeth in the regenerated bone region have been accomplished in dog models using BM-MSC ${ }^{[132-134]}$. Ahn et al ${ }^{[135]}$ reported the first case of regeneration of an alveolar cleft defect. Patient-specific 3D-printed bioresorbable polycaprolactone (PCL) scaffolds were seeded with iliac BM-MSC and showed 45\% defect regeneration 6 months after transplantation, with a $75 \%$ bone mineral density compared to the surrounding bone. AD-MSC, due to their availability and easy handling, are excellent candidates for tissue engineering in CLP patients. Preclinical studies comparing bone regeneration between $\mathrm{AD}-\mathrm{MSC}$ and autogenous bone graft in canine maxillary alveolar cleft models showed no significant differences, meaning AD-MSC can be an acceptable alternative ${ }^{[136]}$. However, clinical studies are needed to confirm their efficacy and reproducibility in humans.

Unlike other alternatives, MSC derived from dental tissues have been studied for CLP patients due to their higher accessibility and less invasive retrieval. Lee et al. ${ }^{[137]}$ reported that stem cells from human exfoliated deciduous teeth (SHEDs) have mineralization potential after expressing bone-specific osteogenic markers following insertion into ex vivo-cultured embryonic palatal shelves and in novo culture. Furthermore, Nakajima et al. ${ }^{[138]}$ compared the bone regeneration ability of SHEDs, BM-MSC, and dental pulp stem cells in mice. They concluded that after 12 weeks of transplantation, the ratio of new bone formation was not significantly different among these groups. However, SHED produced the largest osteoid and widely distributed collagen fibers. Up until now, no clinical studies have been conducted using SHEDs. Although a huge effort has been devoted to the use of tissue engineering as a solution for treating bone defects, more evidence is still needed. 


\section{CONCLUSION}

Mesenchymal stem cells are an emerging alternative for tissue engineering therapies. Besides their differentiation ability, they also express paracrine functions, which have shown to be immunomodulatory and anti-inflammatory. Taking advantage of these functions, MSC have been studied in different fields for the medical treatment of degenerative and congenital diseases. Despite favorable findings in preclinical studies, more clinical studies following all the steps described in translational medicine are needed to address their efficacy, safety, and clinical application. The complexity of these technologies must be considered carefully, and every country must follow a single regulatory pathway.

\section{DECLARATIONS}

\section{Acknowledgements}

The authors would like to thank Mariana Rodríguez for copy-editing this paper.

\section{Authors' contributions}

Written and analyzed all topics, Veasquillo mainly in microtia: Velasquillo C, Madrazo-Ibarra A Mayor contribution on microtia studies: Gutiérrez-Gómez C

Cleft lip and palate: Pérez-Dosal MR

Mayor contribution on stem cells applications in tissue engineering: Melgarejo-Ramírez Y

Mayor contribution articular degenerative diseases: Madrazo-Ibarra A, Ibarra C

\section{Availability of data and materials}

Reviewed several papers already published.

\section{Financial support and sponsorship}

This research work was supported by SECTEI under the project SECTEI-/183/2019 (10160c19).

\section{Conflicts of interest}

All authors declared that there are no conflicts of interest.

\section{Ethical approval and consent to participate}

Not applicable.

\section{Consent for publication}

Not applicable.

\section{Copyright}

(c) The Author(s) 2020.

\section{REFERENCES}

1. NCI Dictionary of Cancer Terms [Internet]. National Cancer Institute. 2011. Available from: https://www.cancer.gov/publications/ dictionaries/cancer-terms [Last accessed on 12 Jun 2020]

2. Dominici M, Le Blanc K, Mueller I, Slaper-Cortenbach I, Marini F, et al. Minimal criteria for defining multipotent mesenchymal stromal cells. The International Society for Cellular Therapy position statement. Cytotherapy 2006;8:315-7.

3. Blau HM, Daley GQ. Stem cells in the treatment of disease. N Engl J Med 2019;380:1748-60.

4. Glenn JD. Mesenchymal stem cells: emerging mechanisms of immunomodulation and therapy. World J Stem Cells 2014;6:526.

5 Maumus M, Jorgensen C, Noël D. Mesenchymal stem cells in regenerative medicine applied to rheumatic diseases: role of secretome and exosomes. Biochimie 2013;95:2229-34.

6. Niu CC, Lin SS, Yuan LJ, Chen LH, Pan TL, et al. Identification of mesenchymal stem cells and osteogenic factors in bone marrow aspirate and peripheral blood for spinal fusion by flow cytometry and proteomic analysis. J Orthop Surg 2014;9:32.

7. Samsonraj RM, Rai B, Sathiyanathan P, Puan KJ, Rötzschke O, et al. Establishing criteria for human mesenchymal stem cell potency: 
establishing criteria for hMSC potency. Stem Cells 2015;33:1878-91.

8. Ben Nasr M, Vergani A, Avruch J, Liu L, Kefaloyianni E, et al. Co-transplantation of autologous MSC delays islet allograft rejection and generates a local immunoprivileged site. Acta Diabetol 2015;52:917-27.

9. Ferreira ML, Silva PC, Alvarez Silva LH, Bonfim DC, Conilho Macedo Müller LC, et al. Heterologous mesenchymal stem cells successfully treat femoral pseudarthrosis in rats. J Transl Med 2012;10:51.

10. Rodriguez RL, Frazier T, Bunnell BA, Mouton CA, March KL, et al. Arguments for a different regulatory categorization and framework for stromal vascular fraction. Stem Cells Dev 2020;29:257-62.

11. Chu DT, Nguyen Thi Phuong T, Tien NLB, Tran DK, Minh LB, et al. Adipose tissue stem cells for therapy: an update on the progress of isolation, culture, storage, and clinical application. J Clin Med 2019;8:917.

12. Lander EB, Berman MH. Autologous stromal vascular fraction: a new era of personal cell therapy. Stem Cells Res Dev Ther 2018;4:1-6.

13. Osteoarthritis Research Society International (OARSI) [Internet]. Available from: https://www.oarsi.org/ [Last accessed on 12 Jun 2020]

14. GBD Compare | IHME Viz Hub [Internet]. Available from: http://vizhub.healthdata.org/gbd-compare [Last accessed on 12 Jun 2020]

15. Woolf AD, Pfleger B. Burden of major musculoskeletal conditions. Bull World Health Organ 2003;81:646-56.

16. Hunter DJ, Bierma-Zeinstra S. Osteoarthritis. Lancet 2019;393:1745-59.

17. Martel-Pelletier J, Barr AJ, Cicuttini FM, Conaghan PG, Cooper C, et al. Osteoarthritis. Nat Rev Dis Primer 2016;2:16072.

18. McAlindon TE, Bannuru RR, Sullivan MC, Arden NK, Berenbaum F, et al. OARSI guidelines for the non-surgical management of knee osteoarthritis. Osteoarthritis Cartilage 2014;22:363-88.

19. Villalobos Córdoba FE, Izaguirre A, Almazan A, Cruz F, Pérez Jiménez FJ, et al. Articular cartilage injuries in 1,309 knee arthroscopies, a public health problem in a developing country? Osteoarthritis Cartilage 2007;15:B102.

20. Brittberg M, Lindahl A, Nilsson A, Ohlsson C, Isaksson O, et al. Treatment of deep cartilage defects in the knee with autologous chondrocyte transplantation. N Engl J Med 1994;331:889-95.

21. Everhart JS, Campbell AB, Abouljoud MM, Kirven JC, Flanigan DC. Cost-efficacy of knee cartilage defect treatments in the United States. Am J Sports Med 2019;363546519834557.

22. Orth P, Gao L, Madry H. Microfracture for cartilage repair in the knee: a systematic review of the contemporary literature. Knee Surg Sports Traumatol Arthrosc 2020;28:670-706.

23. Thorlund JB, Juhl CB, Roos EM, Lohmander LS. Arthroscopic surgery for degenerative knee: systematic review and meta-analysis of benefits and harms. BMJ 2015;350:h2747.

24. Lohmander LS, Hellot S, Dreher D, Krantz EFW, Kruger DS, et al. Intraarticular sprifermin (recombinant human fibroblast growth factor 18) in knee osteoarthritis: a randomized, double-blind, placebo-controlled trial: sprifermin effects in knee osteoarthritis. Arthritis Rheumatol 2014;66:1820-31.

25. Zhang W, Ouyang H, Dass CR, Xu J. Current research on pharmacologic and regenerative therapies for osteoarthritis. Bone Res 2016;4:15040.

26. Poulet B, Staines KA. New developments in osteoarthritis and cartilage biology. Curr Opin Pharmacol 2016;28:8-13.

27. Wang AT, Feng Y, Jia HH, Zhao M, Yu H. Application of mesenchymal stem cell therapy for the treatment of osteoarthritis of the knee: a concise review. World J Stem Cells 2019;11:222-35.

28. Ibarra C, Izaguirre A, Villalobos E, Masri M, Lombardero G, et al. Follow-up of a new arthroscopic technique for implantation of matrixencapsulated autologous chondrocytes in the knee. Arthrosc J Arthrosc Relat Surg 2014;30:715-23.

29. Villalobos E, Madrazo-Ibarra A, Martínez V, Olivos-Meza A, Velasquillo C, et al. Arthroscopic matrix-encapsulated autologous chondrocyte implantation: a pilot multicenter investigation in Latin America. Cartilage 2020;11.

30. Brittberg M, Recker D, Ilgenfritz J, Saris DBF, Summit Extension Study Group. Matrix-applied characterized autologous cultured chondrocytes versus microfracture: five-year follow-up of a prospective randomized trial. Am J Sports Med 2018;46:1343-51.

31. Schuette HB, Kraeutler MJ, McCarty EC. Matrix-assisted autologous chondrocyte transplantation in the knee: a systematic review of mid- to long-term clinical outcomes. Orthop J Sports Med 2017;5:232596711770925.

32. MACI (Autologous Cultured Chondrocytes on a Porcine Collagen Membrane). Available from: https://www.fda.gov/vaccines-bloodbiologics/cellular-gene-therapy-products/maci-autologous-cultured-chondrocytes-porcine-collagen-membrane [Last accessed on 12 Jun 2020]

33. Okano T, Yamada N, Sakai H, Sakurai Y. A novel recovery system for cultured cells using plasma-treated polystyrene dishes grafted with poly(N-isopropylacrylamide). J Biomed Mater Res 1993;27:1243-51.

34. Mitani G, Sato M, Lee JIK, Kaneshiro N, Ishihara M, et al. The properties of bioengineered chondrocyte sheets for cartilage regeneration. BMC Biotechnol 2009;9:17.

35. Kaneshiro N, Sato M, Ishihara M, Mitani G, Sakai H,et al. Bioengineered chondrocyte sheets may be potentially useful for the treatment of partial thickness defects of articular cartilage. Biochem Biophys Res Commun 2006;349:723-31.

36. Sato M, Yamato M, Hamahashi K, Okano T, Mochida J. Articular cartilage regeneration using cell sheet technology. Anat Rec (Hoboken) 2014;297:36-43.

37. Demoor M, Ollitrault D, Gomez-Leduc T, Bouyoucef M, Hervieu M, et al. Cartilage tissue engineering: Molecular control of chondrocyte differentiation for proper cartilage matrix reconstruction. Biochim Biophys Acta 2014;1840:2414-40.

38. Barron V, Merghani K, Shaw G, Coleman CM, Hayes JS, et al. Evaluation of cartilage repair by mesenchymal stem cells seeded on a PEOT/PBT scaffold in an osteochondral defect. Ann Biomed Eng 2015;43:2069-82.

39. Qi BW, Yu AX, Zhu SB, Zhou M, Wu G. Chitosan/poly(vinyl alcohol) hydrogel combined with Ad-hTGF- $\beta 1$ transfected mesenchymal stem cells to repair rabbit articular cartilage defects. Exp Biol Med 2013;238:23-30. 
40. Kim YS, Kwon OR, Choi YJ, Suh DS, Heo DB, et al. Comparative matched-pair analysis of the injection versus implantation of mesenchymal stem cells for knee osteoarthritis. Am J Sports Med 2015;43:2738-46.

41. Majewski M, Susanne H, Klaus S. Epidemiology of athletic knee injuries: a 10-year study. The Knee 2006;13:184-8.

42. Dhollander A, Verdonk P, Verdonk R. Treatment of painful, irreparable partial meniscal defects with a polyurethane scaffold: midterm clinical outcomes and survival analysis. Am J Sports Med 2016;44:2615-21.

43. Ahmed AM, Burke DL. In-vitro measurement of static pressure distribution in synovial joints--Part I: tibial surface of the knee. J Biomech Eng 1983;105:216-25.

44. Baratz ME, Fu FH, Mengato R. Meniscal tears: the effect of meniscectomy and of repair on intraarticular contact areas and stress in the human knee. A preliminary report. Am J Sports Med 1986;14:270-5.

45. Roos H, Laurén M, Adalberth T, Roos EM, Jonsson K, et al. Knee osteoarthritis after meniscectomy: prevalence of radiographic changes after twenty-one years, compared with matched controls. Arthritis Rheum 1998;41:687-93.

46. Leroy A, Beaufils P, Faivre B, Steltzlen C, Boisrenoult P, et al. Actifit ${ }^{\circledR}$ polyurethane meniscal scaffold: MRI and functional outcomes after a minimum follow-up of 5 years. Orthop Traumatol Surg Res OTSR 2017;103:609-14.

47. Schüttler KF, Haberhauer F, Gesslein M, Heyse TJ, Figiel J, et al. Midterm follow-up after implantation of a polyurethane meniscal scaffold for segmental medial meniscus loss: maintenance of good clinical and MRI outcome. Knee Surg Sports Traumatol Arthrosc Off J ESSKA 2016;24:1478-84.

48. Angele P, Johnstone B, Kujat R, Zellner J, Nerlich M, et al. Stem cell based tissue engineering for meniscus repair. J Biomed Mater Res A 2008;85:445-55.

49. Dutton AQ, Choong PF, Goh JCH, Lee EH, Hui JHP. Enhancement of meniscal repair in the avascular zone using mesenchymal stem cells in a porcine model. J Bone Joint Surg Br 2010;92:169-75.

50. Olivos-Meza A, Pérez Jiménez FJ, Granados-Montiel J, Landa-Solís C, Cortés González S, et al. First clinical application of polyurethane meniscal scaffolds with mesenchymal stem cells and assessment of cartilage quality with T2 mapping at 12 months. Cartilage 2019;194760351985241.

51. Lai RC, Yeo RWY, Lim SK. Mesenchymal stem cell exosomes. Semin Cell Dev Biol 2015;40:82-8.

52. Chen TS, Lai RC, Lee MM, Choo ABH, Lee CN, et al. Mesenchymal stem cell secretes microparticles enriched in pre-microRNAs. Nucleic Acids Res 2010;38:215-24.

53. Karlsen TA, Jakobsen RB, Mikkelsen TS, Brinchmann JE. microRNA-140 targets RALA and regulates chondrogenic differentiation of human mesenchymal stem cells by translational enhancement of SOX9 and ACAN. Stem Cells Dev 2014;23:290-304.

54. Liang Y, Duan L, Xiong J, Zhu W, Liu Q, et al. E2 regulates MMP-13 via targeting miR-140 in IL-1 $\beta$-induced extracellular matrix degradation in human chondrocytes. Arthritis Res Ther 2016;18:105.

55. Miyaki S, Sato T, Inoue A, Otsuki S, Ito Y, et al. MicroRNA-140 plays dual roles in both cartilage development and homeostasis. Genes Dev 2010;24:1173-85.

56. Tao SC, Yuan T, Zhang YL, Yin WJ, Guo SC, et al. Exosomes derived from miR-140-5p-overexpressing human synovial mesenchymal stem cells enhance cartilage tissue regeneration and prevent osteoarthritis of the knee in a rat model. Theranostics 2017;7:180-95.

57. Yu XM, Meng HY, Yuan XL, Wang Y, Guo QY, et al. MicroRNAs' involvement in osteoarthritis and the prospects for treatments. Evid Based Complement Alternat Med 2015;2015:1-13.

58. Toh WS. MSC exosome as a cell-free MSC therapy for cartilage regeneration: Implications for osteoarthritis treatment. Dev Biol 2017;9.

59. Toghraie F, Razmkhah M, Gholipour MA, Faghih Z, Chenari N, et al. Scaffold-free adipose-derived stem cells (ASCs) improve experimentally induced osteoarthritis in rabbits. Arch Iran Med 2012;15:495-9.

60. Zhou J, Wang Y, Liu Y, Zeng H, Xu H, et al. Adipose derived mesenchymal stem cells alleviated osteoarthritis and chondrocyte apoptosis through autophagy inducing. J Cell Biochem 2019;120:2198-212.

61. Im GI, Shin YW, Lee KB. Do adipose tissue-derived mesenchymal stem cells have the same osteogenic and chondrogenic potential as bone marrow-derived cells? Osteoarthritis Cartilage 2005;13:845-53.

62. Gentile P, Scioli MG, Bielli A, Orlandi A, Cervelli V. Concise review: the use of adipose-derived stromal vascular fraction cells and platelet rich plasma in regenerative plastic surgery. Stem Cells 2017;117-34.

63. MEDIPOST - The Future of Biotechnology [Internet]. Available from: http://www.medi-post.com/front/eng/stemcell/cartistem.do [Last accessed on 12 Jun 2020]

64. Park Y, Ha C, Lee C, Yoon YC, Park Y. Cartilage regeneration in osteoarthritic patients by a composite of allogeneic umbilical cord blood-derived mesenchymal stem cells and hyaluronate hydrogel: results from a clinical trial for safety and proof-of-concept with 7 years of extended follow-up. Stem Cells Transl Med 2017;6:613-21.

65. Congenital anomalies [Internet]. Available from: https:/www.who.int/news-room/fact-sheets/detail/congenital-anomalies [Last accessed on 12 Jun 2020]

66. Holmes LB. Congenital malformations. N Engl J Med 1976;295:204-7.

67. Corsello G, Giuffrè M. Congenital malformations. J Matern Fetal Neonatal Med 2012;25:25-9.

68. Kumar V, Abbas A, Aster J. Robbins basic pathology. 10th Edition. Elsevier; 2017. p. 952.

69. Suutarla S, Rautio J, Ritvanen A, Ala-Mello S, Jero J, et al. Microtia in Finland: comparison of characteristics in different populations. Int J Pediatr Otorhinolaryngol 2007;71:1211-7.

70. Eavey RD. Microtia and significant auricular malformation. Ninety-two pediatric patients. Arch Otolaryngol Head Neck Surg 1995;121:57-62.

71. Kelley PE, Scholes MA. Microtia and congenital aural atresia. Otolaryngol Clin North Am 2007;40:61-80, vi. 
72. Aguinaga-Ríos M, Frías S, Arenas-Aranda DJ, Morán-Barroso VF. Microtia-atresia: aspectos clínicos, genéticos y genómicos. Bol Méd Hosp Infant México 2014;71:387-95.

73. Anderka MT, Lin AE, Abuelo DN, Mitchell AA, Rasmussen SA. Reviewing the evidence for mycophenolate mofetil as a new teratogen: case report and review of the literature. Am J Med Genet A 2009;149A:1241-8.

74. González-Andrade F, López-Pulles R, Espín VH, Paz-y-Miño C. High altitude and microtia in Ecuadorian patients. J Neonatal-Perinat Med 2010;3:109-16.

75. Luquetti DV, Leoncini E, Mastroiacovo P. Microtia-anotia: a global review of prevalence rates. Birth Defects Res A Clin Mol Teratol 2011;91:813-22.

76. Tanzer RC. Total reconstruction of the external ear. Plast Reconstr Surg Transplant Bull 1959;23:1-15.

77. Brent B. The correction of mi-rotia with autogenous cartilage grafts: I. The classic deformity? Plast Reconstr Surg 1980;66:1-12.

78. Peer LA. Extended use of diced cartilage grafts. Plast Reconstr Surg 1946;1954;14:178-85.

79. Vacanti CA, Vacanti JP. Bone and cartilage reconstruction with tissue engineering approaches. Otolaryngol Clin North Am 1994;27:26376.

80. Rodriguez A, Cao YL, Ibarra C, Pap S, Vacanti M, et al. Characteristics of cartilage engineered from human pediatric auricular cartilage. Plast Reconstr Surg 1999;103:1111-9.

81. Otto IA, Melchels FPW, Zhao X, Randolph MA, Kon M, et al. Auricular reconstruction using biofabrication-based tissue engineering strategies. Biofabrication 2015;7:032001.

82. Cohen BP, Hooper RC, Puetzer JL, Nordberg R, Asanbe O, et al. Long-term morphological and microarchitectural stability of tissueengineered, patient-specific auricles in vivo. Tissue Eng Part A 2016;22:461-8.

83. Liao HT, Zheng R, Liu W, Zhang WJ, Cao Y, et al. Prefabricated, ear-shaped cartilage tissue engineering by scaffold-free porcine chondrocyte membrane. Plast Reconstr Surg 2015;135:313e.

84. Zhou G, Jiang H, Yin Z, Liu Y, Zhang Q, et al. In vitro regeneration of patient-specific ear-shaped cartilage and its first clinical application for auricular reconstruction. EBioMedicine 2018;28:287-302.

85. Kamil SH, Vacanti MP, Vacanti CA, Eavey RD. Microtia chondrocytes as a donor source for tissue-engineered cartilage. Laryngoscope 2004;114:2187-90.

86. Domm C, Schünke M, Christesen K, Kurz B. Redifferentiation of dedifferentiated bovine articular chondrocytes in alginate culture under low oxygen tension. Osteoarthritis Cartilage 2002;10:13-22.

87. Gu Y, Kang N, Dong P, Liu X, Wang Q, et al. Chondrocytes from congenital microtia possess an inferior capacity for in vivo cartilage regeneration to healthy ear chondrocytes. J Tissue Eng Regen Med 2018;12:e1737-46.

88. Hendriks J, Riesle J, Ca van B. Co-culture in cartilage tissue engineering. J Tissue Eng Regen Med 2007;1:170-8.

89. Cai Z, Pan B, Jiang H, Zhang L. Chondrogenesis of human adipose-derived stem cells by in vivo co-graft with auricular chondrocytes from Microtia. Aesthetic Plast Surg 2015;39:431-9.

90. Goh BS, Che Omar SN, Ubaidah MA, Saim L, Sulaiman S, et al. Chondrogenesis of human adipose derived stem cells for future microtia repair using co-culture technique. Acta Otolaryngol (Stockh) 2017;137:432-41.

91. Kang N, Liu X, Guan Y, Wang J, Gong F, et al. Effects of co-culturing BMSC and auricular chondrocytes on the elastic modulus and hypertrophy of tissue engineered cartilage. Biomaterials 2012;33:4535-44.

92. Morrison KA, Cohen BP, Asanbe O, Dong X, Harper A, et al. Optimizing cell sourcing for clinical translation of tissue engineered ears. Biofabrication 2016;9:015004.

93. Pleumeekers MM, Nimeskern L, Koevoet WLM, Karperien M, Stok KS, et al. Cartilage regeneration in the head and neck area: combination of ear or nasal chondrocytes and mesenchymal stem cells improves cartilage production. Plast Reconstr Surg 2015;136:762e74.

94. Zhang X, Xue K, Zhou J, Xu P, Huang H, et al. Chondrogenic differentiation of bone marrow-derived stem cells cultured in the supernatant of elastic cartilage cells. Mol Med Rep 2015;12:5355-60.

95. Cohen BP, Bernstein JL, Morrison KA, Spector JA, Bonassar LJ. Tissue engineering the human auricle by auricular chondrocytemesenchymal stem cell co-implantation. In: Lammi MJ, editor. PLoS One 2018;13:e0202356.

96. Arrendares S, Lisker R. Análisis genético del labio y paladar hendido solo. Estudio en población mexicana. Rev Invest Clin 1974;26.

97. Trigos-Micoló I, Figueroa MEG y L. Análisis de la incidencia, prevalencia y atención del labio y paladar hendido en México. Cir Plástica 2003;13:35-9.

98. Taher A. Cleft lip and palate: lesions, pathophysiology, and primary treatment. J Craniofac Surg 2001;12:200.

99. Vig KW. Alveolar bone grafts: the surgical/orthodontic management of the cleft maxilla. Ann Acad Med Singapore 1999;28:721-7.

100. Waite PD, Waite DE. Bone grafting for the alveolar cleft defect. Semin Orthod 1996;2:192-6.

101. Lilja J, Kalaaji A, Friede H, Elander A. Combined bone grafting and delayed closure of the hard palate in patients with unilateral cleft lip and palate: facilitation of lateral incisor eruption and evaluation of indicators for timing of the procedure.Cleft Palate Craniofac J 2000;37:98-105.

102. da Silva Filho OG, Teles SG, Ozawa TO, Filho LC. Secondary bone graft and eruption of the permanent canine in patients with alveolar clefts: literature review and case report. Angle Orthod 2000;70:174-8.

103. Eufinger H, Leppänen H. Iliac crest donor site morbidity following open and closed methods of bone harvest for alveolar cleft osteoplasty. J Craniomaxillofac Surg 2000;28:31-8.

104. Dawson KH, Egbert MA, Myall RW. Pain following iliac crest bone grafting of alveolar clefts. J Craniomaxillofac Sur 1996;24:151-4.

105. Steinberg B, Padwa BL, Boyne P, Kaban L. State of the art in oral and maxillofacial surgery: treatment of maxillary hypoplasia and 
anterior palatal and alveolar clefts. Cleft Palate Craniofac J 1999;36:283-91.

106. Schliephake H, Dard M, Planck H, Hierlemann H, Stern U. Alveolar ridge repair using resorbable membranes and autogenous bone particles with simultaneous placement of implants: an experimental pilot study in dogs. Int J Oral Maxillofac Implants 2000;15:364-73.

107. Rüdiger SG, Ehmke B, Hommens A, Karch H, Flemmig TF. Guided tissue regeneration using a polylactic acid barrier. Part I: Environmental effects on bacterial colonization. J Clin Periodontol 2003;30:19-25.

108. Mellonig JT, Nevins M, Sanchez R. Evaluation of a bioabsorbable physical barrier for guided bone regeneration. Part II. Material and a bone replacement graft. Int J Periodontics Restorative Dent 1998;18:129-37.

109. Lekovic V, Camargo PM, Weinlaender M, Kenney EB, Vasilic N. Combination use of bovine porous bone mineral, enamel matrix proteins, and a bioabsorbable membrane in intrabony periodontal defects in humans. J Periodontol 2001;72:583-9.

110. Piette E, Alberius P, Samman N, Linde A. Experience with e-PTFE membrane application to bone grafting of cleft maxilla. Int J Oral Maxillofac Surg 1995;24:327-32.

111. Puumanen K, Kellomäki M, Ritsilä V, Böhling T, Törmälä P, et al. A novel bioabsorbable composite membrane of Polyactive 70/30 and bioactive glass number 13--93 in repair of experimental maxillary alveolar cleft defects. J Biomed Mater Res B Appl Biomater 2005;75:25-33.

112. Aichelmann-Reidy ME, Heath CD, Reynolds MA. Clinical evaluation of calcium sulfate in combination with demineralized freeze-dried bone allograft for the treatment of human intraosseous defects. J Periodontol 2004;75:340-7.

113. Yukna RA, Krauser JT, Callan DP, Evans GH, Cruz R, et al. Multi-center clinical comparison of combination anorganic bovine-derived hydroxyapatite matrix (ABM)/cell binding peptide (P-15) and ABM in human periodontal osseous defects. 6-month results. J Periodontol 2000;71:1671-9.

114. Kiliç AR, Efeoğlu E, Yilmaz S. Guided tissue regeneration in conjunction with hydroxyapatite-collagen grafts for intrabony defects. A clinical and radiological evaluation. J Clin Periodontol 1997;24:372-83.

115. Rabie AB, Chay SH. Clinical applications of composite intramembranous bone grafts. Am J Orthod Dentofac Orthop 2000;117:375-83.

116. Méndez R, López-Cedrún JL, Patiño B, Vázquez I, Martín-Sastre R, et al. Platelet-rich plasma (platelet gel) in secondary alveoloplasty in cleft patients. Cir Pediatr 2006;19:23-6.

117. Segura-Castillo JL, Aguirre-Camacho H, González-Ojeda A, Michel-Perez J. Reduction of bone resorption by the application of fibrin glue in the reconstruction of the alveolar cleft. J Craniofac Surg 2005;16:105-12.

118. Zybutz MD, Laurell L, Rapoport DA, Persson GR. Treatment of intrabony defects with resorbable materials, non-resorbable materials and flap debridement. J Clin Periodontol 2000;27:169-78.

119. Boyne PJ. Application of bone morphogenetic proteins in the treatment of clinical oral and maxillofacial osseous defects. J Bone Joint Surg Am 2001;83:S146-50.

120. Peled M, Aizenbud D, Horwitz J, Machtei EE. Treatment of osseous cleft palate defects: a preliminary evaluation of novel treatment modalities. Cleft Palate-Craniofacial J 2005;42:344-8.

121. Trejo PM, Weltman R, Caffesse R. Treatment of intraosseous defects with bioabsorbable barriers alone or in combination with decalcified freeze-dried bone allograft: a randomized clinical trial. J Periodontol 2000;71:1852-61.

122. Murphy KG, Gunsolley JC. Guided tissue regeneration for the treatment of periodontal intrabony and furcation defects. A systematic review. Ann Periodontol 2003;8:266-302.

123. Carpio L, Loza J, Lynch S, Genco R. Guided bone regeneration around endosseous implants with anorganic bovine bone mineral. A randomized controlled trial comparing bioabsorbable versus non-resorbable barriers. J Periodontol 2000;71:1743-9.

124. Reynolds MA, Aichelmann-Reidy ME, Branch-Mays GL, Gunsolley JC. The efficacy of bone replacement grafts in the treatment of periodontal osseous defects. A systematic review. Ann Periodontol 2003;8:227-65.

125. Nyberg EL, Farris AL, Hung BP, Dias M, Garcia JR, et al. 3D-printing technologies for craniofacial rehabilitation, reconstruction, and regeneration. Ann Biomed Eng 2017;45:45-57.

126. Hixon KR, Melvin AM, Lin AY, Hall AF, Sell SA. Cryogel scaffolds from patient-specific 3D-printed molds for personalized tissueengineered bone regeneration in pediatric cleft-craniofacial defects. J Biomater Appl 2017;32:598-611.

127. Martín-Del-Campo M, Rosales-Ibañez R, Rojo L. Biomaterials for Cleft Lip and Palate Regeneration. Int J Mol Sci 2019;20.

128. Gerhardt LC, Boccaccini AR. Bioactive glass and glass-ceramic scaffolds for bone tissue engineering. Mater Basel Switz 2010;3:3867910.

129. Janssen NG, de Ruiter AP, van Hout WMMT, van Miegem V, Gawlitta D, et al. Microstructured $\beta$-tricalcium phosphate putty versus autologous bone for repair of alveolar clefts in a goat model. Cleft Palate-Craniofacial J 2017;54:699-706.

130. Al-Ahmady HH, Abd Elazeem AF, Bellah Ahmed NEM, Shawkat WM, Elmasry M, et al. Combining autologous bone marrow mononuclear cells seeded on collagen sponge with Nano Hydroxyapatite, and platelet-rich fibrin: reporting a novel strategy for alveolar cleft bone regeneration. J Craniomaxillofac Surg 2018;46:1593-600.

131. Batool F, Strub M, Petit C, Bugueno IM, Bornert F, et al. Periodontal tissues, maxillary jaw bone, and tooth regeneration approaches: from animal models analyses to clinical applications. Nanomater Basel Switz 2018;8.

132. Yoshioka M, Tanimoto K, Tanne Y, Sumi K, Awada T, et al. Bone regeneration in artificial jaw cleft by use of carbonated hydroxyapatite particles and mesenchymal stem cells derived from iliac bone. Int J Dent 2012;2012:352510.

133. Tanimoto K, Sumi K, Yoshioka M, Oki N, Tanne Y, et al. Experimental tooth movement into new bone area regenerated by use of bone marrow-derived mesenchymal stem cells. Cleft Palate Craniofac J 2015;52:386-94.

134. Sumi K, Abe T, Kunimatsu R, Oki N, Tsuka Y, et al. The effect of mesenchymal stem cells on chemotaxis of osteoclast precursor cells. J Oral Sci 2018;60:221-5. 
135. Ahn G, Lee JS, Yun WS, Shim JH, Lee UL. Cleft alveolus reconstruction using a three-dimensional printed bioresorbable scaffold with human bone marrow cells. J Craniofac Surg 2018;29:1880-3.

136. Pourebrahim N, Hashemibeni B, Shahnaseri S, Torabinia N, Mousavi B, et al. A comparison of tissue-engineered bone from adiposederived stem cell with autogenous bone repair in maxillary alveolar cleft model in dogs. Int J Oral Maxillofac Surg 2013;42:562-8.

137. Lee JM, Kim HY, Park JS, Lee DJ, Zhang S, et al. Developing palatal bone using human mesenchymal stem cell and stem cells from exfoliated deciduous teeth cell sheets. J Tissue Eng Regen Med 2019;13:319-27.

138. Nakajima K, Kunimatsu R, Ando K, Ando T, Hayashi Y, et al. Comparison of the bone regeneration ability between stem cells from human exfoliated deciduous teeth, human dental pulp stem cells and human bone marrow mesenchymal stem cells. Biochem Biophys Res Commun 2018;497:876-82. 